\title{
ВклаА Тюркских Мыслителей В Мировое Наследие
}

\author{
СевАа СУ $\Lambda$ ӖМАНОВА ${ }^{1}$
}

\section{Аннотация}

В статье говорится о культурном возрождении тюрко-мусульманских народов после падения Халифата и образования независимых феодальных государств на исторической территории Азербайджана и Центральной Азии. Именно в этот период и в период монгольских нашествий появились такие выдающиеся ученые - мыслители как Ибн Сина, ал-Фараби, ал-Бируни, ал-Хорезми, НасирадАин Туси и многие Аругие, научные открытия которых внесли огромный вклаА в мировое наследие. Произведения Махмуда Кашкари и Юсуфа Баласагуни, а также эпосы «Манас» и «Книга Аеде Коркуда» сыграли важную роль в изучении этнических корней, обычаев, быта, культуры и истории тюркских народов. Распространение Халифатом ислама среди тюркских народов еще больше обогатила их культуру приобщив к исламской культуре. Моральное состояние вставшего «на путь истины», оставило наглядный слеА в дастанах эпоса «Книга Аеде Коркуда». В них хотя огузы называются мусульманами, тем не менее в их быту ведущее место занимает Аревнетюркское божество Тенгри. Таким образом цель в написании этой статьи заключается в том, что именно тюркские ученые открыли первый университет- медресе Низамиййе, Марагинскую обсерваторию, которая была первой академией на Востоке. Таблицы составленные в этой обсерватории были более точными, чем современные пятизначные геометрические таблицы.

Ключевъие Слова: Тюркские мыслители, тюркские народъ, наука, мировое наследие

\section{Contribution of Turkish Thoughts to the World Heritage}

\section{Abstract}

The article refers to the cultural revival of the Turkic-Muslim peoples after the fall of the Caliphate and the formation of independent feudal states on the historical territory of Azerbaijan and Central Asia. It was during this period and during the period of the Mongol invasions that such outstanding scientists appeared - thinkers like Ibn Sina, al-Farabi, al-Biruni, al-Khorezmi, Nasiraddin Tusi and many others whose scientific discoveries made a huge contribution to the world heritage. The works of Mahmoud Kashkari and Yusuf Balasaguni, as well as the epics Manas and The Book of Dede Korkuda, played an important role in the study of ethnic roots, customs, life, culture and history of Turkic peoples. The spread of Islam among the Turkic people by the Caliphate enriched their culture even more by introducing it to Islamic culture. The moral state of embarking "on the path of truth" left a clear mark in the dastans of the epic "The Book of Dede Korkuda". Although Oguzes are called Muslims in them, nevertheless, the ancient Turkic deity Tengri occupies a leading place in their life. Thus, the goal in writing this article is that it was the Turkic scientists who opened the first Nizamiyye Madrasah University, the Maragin Observatory, which was the first academy in the East. The tables compiled at this observatory were more accurate than modern five-digit geometrical tables.

Key Words: Turkic thinkers, Turkic peoples, science, world heritage

\section{Atıf İçin / Please Cite As:}

Сулейманова, С. (2020). ВклаА Тюркских мыслителей в мировое наследие. Manas Sosyal Arastırmalar Dergisi, 9(3), 1926-1933.

Geliş Tarihi / Received Date: 13.03.2019

Kabul Tarihi / Accepted Date: 26.04.2020

\footnotetext{
${ }^{1}$ Prof. Sevda SULEYMANOVA - Bakü Devlet Üniversitesi Tarih Fakültesi, s.u.suleymanova@mail.ru ORCID: 0000-0003-2720-0806
} 


\section{Введение}

Политическое возрождение вследствие падения Халифата дало мощный импульс развитию науки, культуры и искусства у тюркских народов. Возникшие самостоятельные феодальные

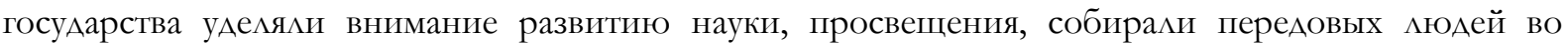
Аворцах, строили мечети, мосты и великолепные Аворцы.

В городах функционировало большое количество медресе, прославившихся на всем Востоке. Первое мелресе под названием Низамиййе (Низамуль-мюльк), которое можно называть первым университетом во всем мире было открыто в 1066 году в БагАаде по приказу Султан Алпарслана. Университет, гАе преподавали теологию, право, филологию, математику и астрономию, имел богатую библиотеку (Özdək, 1993, 104). В действующих при мечетях начальных школах изучали Коран. Накануне падения халифата Азербайджан и Центральная Азия были культурными центрами этой империи. В АзербайАжане были известны такие великие мыслители тюркомусульманского мира как аА-Бируни, Ибн Сина, ал-Фараби, Рудаки, Фирдовси и Ар. Многие из них были напрямую связаны с научно-литературной средой АзербайАжана. В этот период Азербайджан стал одним из центров культурного процесса, известного как «Мусульманское возрождение».

\section{Вемикие тюркские ученые Востока}

Вылающиеся мыслители Востока, в основном были уроженцами Центральной Азии. Великий философ.ал-Фараби получил образование на арабском языке в Бухаре, Аамаске и Багдале. Его настоящее имя Абу Насир МухаммеА ибн МухаммеА ат Тюрки (870-950). Он написал многочисленные произведения по философии и могике. В сочинении «Ихса-ул-У («Количество наук»), Фараби дает классификацию наук. Он считается основателем науки могики после Аристотеля. Фараби также является автором произведений «Фусус-ул хикам», «Сийасат-ул Медениййе», «Медин-ал Фазиле», «Исбат-ул Мефаракат», «Талакат» и Ар. (Сулейманова, 2012, 361).

ОАним из великих деятелей науки Центральной Азии и всего Востока бы Абу Рейхан ацБируни ал-Хорезми (973-1048). Ученый-энциклопедист жил в Газне и написал 196 произведений по философии, истории, географии, математике, астрономии, минералогии, физике и Ар. Он первым за 500 мет до Коперника Аоказал вращение Земли вокруг Солнца. (www.turkosfer.com/biruni/).

Великий ученый Востока Ибн Сина (980-1037) родился в селе Афшанак, которое находилось вблизи Бухары. Его настоящее имя Абу Али Гусейн ибн Аблул^ах, а в Европе он прослав ен как «Авиценна». Ибн Сина написал 5-томник о медицине «А $\Lambda$-ганун фит тибб» (Закон медицинской науки), энциклопедию философских произведений «Шафа», «Фисул» и Ар. Он был единственным хирургом на всем Востоке и написал 250 крупных произведений. Его ученик великий азербайджанский философ Бахманйар ибн Марзбан сыграл существенную роль в развитии мировой философии. Его произведения были переведены на многие восточные и западные языки. (“История Азербайджана. С Аревнейших времен до 70-х гг. ХІХ в.”, 2008, 242)

«Диван-и-люгат-ат-тюрк» Махмуда Кашгари и «Кутадгу-Билиг» Юсуфа Баласагуни считаются великими научными произведениями тюркских народов XI в. Поэма Баласагуни написана в 1069 г., а ее значение «Наука во имя счастья». Город Баласагун, где родился Юсуф, был столицей Караханидов. Поэма была написана на уйгурском языке и подарена правителю Караханидов Сатук Бугра хану. Она посвящена историческим событиям, происходящим в Центральной Азии и Восточном Туркестане. В произведении Ю.Баласагуни много философских мыслей о смысле человеческой жизни, о моральных нормах, а также Аревнетюркские мегенды и фольклор. (Сулейманова, 2009, 236).

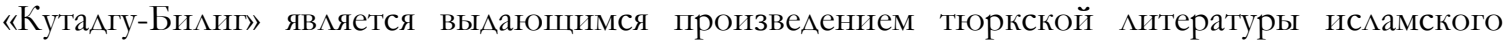
времени, его автор - мыслитель мирового масштаба»- говорил заместитель Генерального секретаря ТЮРКСОЙ профессор Фырат Пурташ на заключительных торжествах Года Юсуфа Баласагуни. (TÜRKSOY, 2017, 40).

Аругое известное произведение этого периода - «Диван-и-люгат-ат-тюрк» Махмуда Кашгари. Он жил в городе Кашгаре. Настоящее имя Махмуд ибн Гусейн. Произведение было написано им в 
1072-1074 гг. на арабском языке. Оно состоит из трех томов и посвящено языку, исторической этнографии и фольклору тюркских народов Центральной Азии. Надо отметить, что именно М.Кашгари впервые назвац 22 племен сельджукских огузов. Он приложил к своему произведению карту, где отметил и Азербайджан в числе тюркских стран.

Азербайджанский философ Эйнельгюззат Мийанечи (1099-1131) создал вылающиеся произведения, но был казнен богословами за свои пантеистические воззрения. Большой известностью пользовался и Хатиб Тебризи (1030-1109), получивший первоначальное образование в Тебризе. Он путешествовац по странам Востока. Поселившись в Багдаде, он проводиц ценные исследования в области философии, Аогики, митературы и языка, став выдающимся ученым исламского мира.

Автор произведения «Аиван-и Хикмет» Ходжа Ахмед Йасави был поэтом-дервишем и сыграл важную роль в культурной жизни Центральной Азии и в пропаганде исламской религии. Он был похоронен в городе Йасе Узбекистана в 1166 г. В его честь в конце XIV в. эмиром Тимуром.была построена мечеть.

Сулейман Бакиргани был современником Йасави. Его прозвище было «Хаким-Ата». Он автор сбора стихов «Бакирган», гАе имеются интересные сведения об истории и этнографии племен, обитавших на побережьях Сырдарьи. Бакирган призывац Аюдей к справедливости и осознанию мыс $и$ о ни вечности человеческой жизни.

\section{Выдающиеся азербайджанские мыскитеми}

В XI-XII вв. появ яется целое поколение азербайлжанских поэтов. ОАним из великих поэтов Востока, чье имя вошло в список классиков мировой поэзии, был Низами (ИАьяс) ГянАжеви. Азербайджанская митература эпохи Возрождения Аостигла своего пика в творчестве Низами.

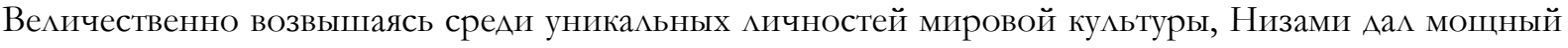
толчок развитию восточной и мировой поэзии. Бессмертная «Хамсе» Низами прославила его во всем мире. Самое большое достижение поэзии Низами состоит в том, что созданный им справеАливый правитель побежАает не только мечом Аичным героизмом, но и умом, знаниями. Он создал свою философию илеального государства, где царят правда и равноправие, на дверях нет замков, нет насилия, не проливается напрасно кровь, серебро и золото не имеют никакой цены, опередив известных утопистов Томаса Мора и Томазо Кампанелму. (“История Азербайджана. С Аревнейших времен до 70-х гг. ХІХ в.”, 2008, 244).

Монгольские походы и завоевания в XIII-XV вв. нанесли большой урон социальноэкономической и культурной жизни тюркских народов. МежАу тем, были заметны и некоторые Аостижения в науке и митературе. В 1259 г. под руководством великого азербайАжанского ученого с энциклопедическими знаниями Насирадлина Туси была построена обсерватория в Мараге. В этой обсерватории трудились более ста ученых из многих стран мира, в том числе и из Центральной Азии АжамаладАин Бухари. 3.В.Тоган пишет, что Хулагу хан пригласив китайских, арабских и Аругих ученых со всего конца мира в Марагу превратиц этот Азербайджанский город в центр мировой науки. (Togan, 1981, 223). Научные труды Марагинской обсерватории занимали большое место в исследованиях обсерватории У угбека в Самарканде. ОАнако Самаркандская обсерватория не смогла оказать такого влияния на последующее развитие астрономической науки какое было оказано Марагинской обсерваторией. Она была первой академией на Востоке. Проведенные здесь исследования и написанные труды мегли в основу европейской науки. Составленные в Марагинской обсерватории таблицы были более точными, чем современные пятизначные геометрические таблицы. Аругая обсерватория была построена в Тебризе в 1300-1304 гг. Она входила в комплекс созданных Газан ханом «Абваб ац-бирр» («Аома Ал^аха»).

Величайший ученый НасирадАин Туси (1201-1274) получил образование у ученых школы Бахманйара и Ибн Сины. В 1230 г. он написал сочинение «Ахлаги-Насири», которое прославило его на Востоке. А его книга «ЗиАж-е Эльхани» («Таблицы Элхани») очень быстро стала известна во всей Европе. В вопросах понятия чисел Н.Туси на 400 лет опередил европейскую науку. Книга «Тахрири-Эглилис» («Толкование Эвклила») оказала влияние на работы вилных европейских ученых. Занимаясь изучением философско-социологических проблем, Н.Туси высоко ценил философские взгляды Абу Али ибн Сины. В работах «Комментарии к философии и могике Ибн Сины», «Постраничные замечания ар-Рази», «Рисале по теологии и метафизике» и в других трудах 
он, защищая философию Ибн Сины, ограждал ее от нападок исламских теологов. В своем сочинении «Рассуждения о Авух рассуждениях» Туси отдельно исследовал философскоперипатетический спор межАу ал-Газали и Ибн-РушАом. Он явАяется автором более 150 научных трудов.(“История Азербайджана. С Аревнейших времен до 70-х гг. XIX в.”, 2008, 313).

В XIII-XV вв. получило распространение открытие «Аомов зАоровья». КАиническое учреждение такого рода впервые было открыто Ибн Синой. В период монгольского правления, по указанию везира Газан хана Ф.РашидадАина уже во многих областях открылись больницы. А Аар уш-шафа в Тебризе, практически был университетским городком, который назывался «РабиРашиди». Он превратился в важный научно-культурный центр, где был создан университетский комплекс с большой биболиотекой.

В это время в философской мысли получили распространение суфийские взгляды. ОАним из великих азербайджанских мыслителей являлся СирацжадАин Урмави (1198-1283), ученыйфилософ, специалист по Аогике и естествознанию. Получив свое образование в Мосуле в школе КамаладАина ибн Йуниса, он стал главным кадием города Коньи. Сочинения «МатаАи аА-анвар» («Рождение света»), «Аатаиф ал-Хикмат» («Тонкости мудрости»), «Байан ал-хакк» («Изложение истины»), «Ар-расаил фи илм ал-АжадаА» («Трактаты о науке по диалектике») и Ар. прославили его имя в научном мире. Сочинение С.Урмави, посвященное Аиалектике, с комментариями ученого XIV в. КутбадАина Рази было издано в Стамбуле, Тебризе и Тегеране.

Выдающийся мыслитель СадедАин шейх Махмуд Шабустари (1284-1320) явАялся знатоком наследия античных философов. Наряду с Аристотелем и Платоном в своих трудах он упоминает имена таких ученых как Ибн Сина, НасирадАин Туси, Газали, Мансур Ха^ладж, Байазид Бистам, Васил иб̆н Ата, Фаридадлин Аттар.

М.Шабустари был пантеистом и придерживался фицософии вахАат-ал-вуджуд. Он явАяется автором сочинений «Гюльшани-раз» («Цветник тайн»), «ШахиАнаме», «СааАатнаме» и Ар., которые оказали влияние на философию всего Востока. В его сочинениях большое место отведено исследованию таких вопросов, как чистота Ауховности божественной суб̆станции, философской трактовке понятий провидение и принужАение, сопоставлению цепи доводов, на которые опирается человеческий разум, с Аогмами Корана. (“История АзербайАжана. С Аревнейших времен Ао 70-х гг. ХIX в.”, 2008, 315).

Суфийский ученый, известный ещё при жизни на мусульманском Востоке ШихабаААин Абу Хафе Омар Сухраверди (1145-1234) был основателем суфийской организации Сухравердиййа. Его книга «Авариф ал-маариф» («Аары знаний») была переведена на турецкий и персидский языки. ХамАулмах Казвини пишет, что Шейх ШихабелАин-и Мактул ал - Сухраверди написал множество книг во главе с «Сандукул-Амел». (Казвини, 2018, 568). Он часто приезжал в Конийский султанат, был гостем султана ИзадАина Кейкавуса. Турецкий историк XIV в. ШамсадАин Афлаки в своем произведении описал встречу Ш.Сухраверди с отцом Мовлана АжалаладАина Руми Бахаадином Валадом - «Султан-ул-улема».

Мовцана Ажалаладлин (1207-1273) Руми был могущественным турецким поэтом-суфием, шейхом и великим представителем философии ислама. Его настоящее имя - Мехмет АжалаладАин. Он жил в Конье, преподавал в медресе, занимался проповедями в мечети. ОАнако встреча с Шамсом Тебризи произвела коренные изменения не только в его взглядах, и - в образе жизни. Мовлана бросил преподавание и проповеди, приобщился к музыке, к танцам дервишей «семави». БАагодаря этой встречи АжалалаАдин Руми стал великим мастером слова - Мовланой (Сулейманова, 2009:241).

Вылающийся азербайджанский мыслитель и поэт ШамсадАин МухаммеА ибн Али Тебризи в феврале 1246 г. покинул Конью. Причиной этому послужило неАовольство многих, его Ауховной близостью с Мовланой. Отвернувшись от общества Мовлана везде искал Шамса и узнав о его местонахожАении, Аобился его возвращения в Конью. Но вскоре Шамс был убит завистниками их Аружбы. А убитый горем Мовлана взял себе псевдоним «Шамс» и написал поА этим именем «Аиван и-Кебир». «Месневи» Мовланы популярны во всем тюркском мире.

Тяжелые социально-экономические последствия монгольских завоеваний способствовали зарождению новых учений, в частности хуруфизма. Создателем этого учения был выдающийся 
мыслитель и поэт Фазлулцах Наими Тебризи ал-Хуруфи (1339/40-1393/4). Теоретическая основа учения хуруфизма была заложена в его книгах «Ажавидани-кебир» («Книга вечности»), «Махаббатнаме», «Аршнаме» и в «Аиване» стихов.

Основное философское воззрение хуруфитов заключается в олицетворении Алмаха с живой природой и с человеком. По мнению Ф.Наими, Алیах проявляется также в словах посреАством букв и цифр. Его учение подАерживали и развивали Насими, СейиА Исхак и др. ОАнако этот период считается периодом застоя в развитии естественных и философских наук. А научные трактаты, в основном состояли из комментариев. Тому пример сочинения СейиА Йахйи Бакуви «Шархи Гульшани-раз», «Асрар ат-Талибин» («Тайны искателей истины»). Список его книги «Раудат ал-улум» («СаА наук») находится в музее Айасофия.

\section{История кумьтурной жизни тюркских народов}

В развитии исторической науки оАним из больших событий явилось созАание под руководством Фазлулмаха РашидадАина многотомного труда «Ажами ат-таварих» («Сбор историй»). ВкАюченный во вторую книгу сочинения «Тарихи-Огуз ва Туркан ва Хекайети-Ажахангири» («Огузнаме») считается одним из ценных источников А^я изучения ранней истории огузских тюрок.

Известный хронист XV в. Аовлатшах СамарканАи, собрав обширный материал о культурной жизни тюркских народов, сыграл неоценимую роль в исследовании их истории культуры XIII-XV вв. По его сообщению, в XIII в. существовац тюркский Аиван Гасаноглу, который был хорошо известен в митературных кругах Азербайджана и Анатолии. Насими, поэты Анатолии ТаАжаАдин Ахмеди, Ахмел АаАж, узбекский поэт Сейф Сарайи и Ар. написали стихи в подражание стихотворению Гасаноглу.

После Гасаноглу, и в Анатолии появился митературный Аиван Кади Бурханадлина Ахмеда на тюркском языке. Он родился в 1344 г. в семье КаАия Кайсери ШамсадАина Мухаммеда. Получив образование в Египте и Сирии, он изучиц фикх, могику, астрономию, математику и медицинские науки. В 1365 г. Бурханадлин Ахмед был назначен кадием города Сивас и в 1381 г. был назначен везиром, а позже наибом. КаАи БурханаАлин создал султанат в Сивасе,.Аиван КаАи БурханадАина на турецком языке, состоящий из 608 страниц, составцяет 17 тыс. строк, куда входят 1319 газелей, 108 туйуков и 20 рубаи.

Величайший народный озан, первопроходец стиха текке Юнус Имре (пр.1240-1320) был знаменосцем чистого турецкого языка и приверженцем философии «вахлати ац-вуджуд». Он активно участвовац в меджлисах Мовланы, путешествовац по Анатолии, Сирии, Азербайджану и Ирану.

В распространении суфизма среди западных тюрков, Юнус Имре сыграл ту же роль, которую сыграл Ахмед Йасави среди восточных тюрков. Он великий поэт, не только митературы суфизма, но и митературы Аиван. Сотни миричесих стихов собраны в его «Аиване» и месневи «РисалетунНусхиййе». Ахмед Фагих, СаййаА Хамза, Ходжа Аехгани, Гюльшахри и Ашуг Паша были создателями турецкой диванской митературы в Анатолии. ( Сулейманова, 2012, 371).

В XVI-XVII вв. в культурной жизни тюркских народов произошли большие позитивные изменения. Города Бухара, Самарканд, Балх, Хисар и Ар. превратились в центры науки Центральной Азии. Величайший представитель тюркской митературы и искусства Алишир Навои (1441-1501) достиг вершины поэзии Физули. Он является автором произведений «Хамса»: «ФархаА и Ширин», «Аейли и Меджнун», - Аивана на тюркском языке, «Хазаин-ац-Маани» и Ар. Навои жил в Герате и наряду с государственными Аелами, занимался созданием произведений музыки, изобразительного и приклаАного искусства.

В конце XVI в. в митературной сфере наблюдалось возрождение. В этом сыграли немалую роль Молца Мушвиг, Туроби, Нахли, Йакта Котли Бухорои, Ходжа Мухаммел Сабир, Гасан бай Рафик Хироти, Молиа Ажамал, Муним, Надим Мохрам и Ар. Многие поэты в своих стихах критиковали жестокость династий Шейбанидов и Аштарханидов и поэтому вынуждены были покинуть родину, продолжая деятельность в ИнАии.

Наблюдалось ослабление влияния суфизма на митературные произведения. Поэзия выдающегося поэта Мирабида Сейид Нафиси, Фитрат Зардуйа, Молма Абил Мумтаз, Молца Мулхаме отражала жизненные условия, желания широких трудящихся масс. 
C проникновением тюркского языка в XVI в. в сферу государственно-Аипломатической переписки в жизнь дворца Сефевидов, азербайджанский митературный язык еще более обогатился. Великие поэты писали на родном тюркском языке. Мастер газелей, касыА и месневи, автор митературного «Аиван»а, «Насихетнаме» и «Аехнаме» шах Исмайыл Хатаи также писал на родном языке.

Самым вылающимся представителем тюркской литературы XVI в. являлся Мухаммед Физули (1498-1556). Он жил в одном из крупных центров науки и культуры Востока Багдаде, который находился в составе империи Сефевидов. Предки Мухаммеда Физули принадлежали к племени Байат. Его творчество как образец Аитературного языка открыло новый этап в развитии тюркского языка. Поэма «Аейли и Меджнун», став жемчужиной мировой митературы, принесла ему большую славу. А Аругое крупное произведение «Бангу-баде» Физули посвятил шаху Исмайылу. Его философские взгляды нашли отражение в труде «Матла ул-этикаА» («Источник веры»), написанном на арабском языке. Наряду с анализом индийской, персидской, азербайджанской философии и философии арабского Востока, в этом сочинении Ааны сведения и античной философии Гераклита, Платона, Аристотеля, Пифагора и Ар. (“История Азербайлжана. С Аревнейших времен до 70-х гг. XIX в.”, 2008, 405).

Известному мастеру слова XVII в. Саибу Тебризи принадлежит сборник из 120 тыс. бейтов. Он наряду с месневи «Кандагарнаме», «Махмуд и Айаз» и несколько Аиванов, написал сочинение «Байаз» из 25 тыс. бейтов. В нем перечислены имена 800 поэтов. Аиван Саиба Тебризи изучался в различных медресе Османской империи как учебное пособие. Его полное имя Мирза Мухаммедали Мирза Аблуррахим оглу.

ОАним из выдающихся эпических памятников Османской империи, Азербайджана и Туркестана явцяется Аастан «Кёроглу». ГАавный герой эпоса решительный и непобедимый сын своего народа, бывший одним из предводителей Авижения Ажелали, считается исторической Аичностью. Так как именно в начале XVII в. усилилось крестьянское Авижение в Анатолии и Азербайджане. Наряду с этим исторические события, имевшие место в разАичные периоды, переплелись межАу собой в эпосе Кёроглу. Аревние тюркские эпосы вдохнули жизнь в новый эпос, который бым широко распространен в Османской империи, на Кавказе, Туркестане и в Аругих странах.

\section{Закиючение}

Таким образом, можно сделать вывод, что наука объективная и поэтому она интернациональная. ОАнако философия совершенно независимая наука. Она может рождать новые и оригинальные гипотезы. 3.Гекалп пишет, что философия не вынуждена быть интернациональной как Аругие науки. Она иногда бывает субъективной и поэтому может быть и национальной. Значит в философии тоже может быть тюркизм. (Göyalp, 1991, 133). Несмотря на то, что тюркские мыслители творили на арабском и персилском языках, и этим вложили большой вклаА в мировое наследие, они все же являются создателями тюркской науки и культуры.

\section{Митература}

ал-Хорезми Мухаммад. (1983) Астрономические трактаты. Ташкент: Фан,

Ардакани, Р. А. (2014) Фараби - основоположник исламской философии. Пер. с перс. А. Абсаликова. Москва, «Салра»

Бируни Абу Рейхан. (1974) Фармакогнозия в медищие / Иссл., пер. и прим. У. И. Каримова // Избр. произв. Т. 4. Ташкент: Фан

Göyalp Z (2010). Türkçülïyün əsaslar, Bakı, Xəzər Universiteti nəşriyyatı

Ибн Сина. (1956-1960) Канон врачебной науки : В 5 т. — Ташкент,. Фан

Ибн Сина. (1976) Послание о любви. Тбилиси: Мецниереба

История Азербайджана. С древнейших времен до 70-х г. ХІХ в. (Под реА. Алиярлы, С.) (2008) Баку, Чыраг Kazvini Hamdullah Müstevfi-yi.(2018) Tarih-i Güæide /Çeviren Prof.Dr.Mürsel Öztürk. Ankara, Türk Tarih Kurumu Мамедбейли Г. А. (1961) Основатель Марагинской обсерватории Насирэдин Туси. Баку, Елм..

Minorsky. (1957) Studies in Caucasian History. Cambridge, Cambridge University Press

Mövlana Colaləddin Rumi. (2015) Masnavi. Bak1

Özdək, R. (1993) Türkün q1zıl kitabı, II kitab, Bak1

Сулейманова, С. (2009) История тюркских народов. С древнейших времен по настоямее время. Баку, Тэксил 
Сулейманова, С. (2012) Из истории тюркских народов. Общее представление о характере исторических прочессов происходивших в истории тюркских народов. LAP Lambert, Saarbrücken.

Туси НасирэдАин. (1952) Трактат о полном четвгрёхстороннике. Баку, ИзА. АН АзССР

Togan Z.V. (1981) Umumi türk taribine giris. c. 1, En eski devirlerden 16. Asra kadar, İstanbul,. TTK yayınları'TÜRKSOY. (2017) Yusuf Has Hacib ynl kapanış gerçekleşdirildi.

www.turkosfer.com./biruni/

\section{EXTENDED ABSTRACT}

Political revival due to the fall of the Caliphate gave a powerful impetus to the development of science, culture and art among the Turkic peoples in the East. Emerging independent feudal states were paid attention to the development of science, enlightenment, collected advanced people in palaces, built mosques, bridges and magnificent palaces. The rulers wanted to show themselves, whole their political and economic power through culture. A large number of madrasas, centers of educations, famous throughout the East, functioned in the cities. Primary schools studied the Koran, the holy book of Islam, in the mosques.

Turkic-Muslim peoples after the fall of the Caliphate and the formation of independent feudal states on the historical territory of Azerbaijan and Central Asia. It was during this period and during the period of the Mongol invasions that such outstanding scientists appeared - thinkers like Ibn Sina, al-Farabi, alBiruni, al-Khorezmi, Nasiraddin Tusi and many others whose scientific discoveries made a huge contribution to the world heritage.

The works of Mahmoud Kashkari and Yusuf Balasaguni, as well as the epics Manas and The Book of Dede Korkuda, played an important role in the study of ethnic roots, customs, life, culture and history of Turkic peoples. The spread of Islam among the Turkic peoples by the Caliphate enriched their culture even more by introducing it to Islamic culture. The moral state of embarking "on the path of truth" left a clear mark in the dastans of the epic "The Book of Dede Korkuda". Although Oguzes are called Muslims in them, nevertheless, the ancient Turkic deity Tengri occupies a leading place in their life.

Thus, the goal in writing this article is that it was the Turkic scientists who opened the first Nizamiyye Madrasah University, the Maragin Observatory, which was the first academy in the East. The tables compiled at this observatory were more accurate than modern five-digit geometrical tables.

The well-known mathematician, prominent scientist Abu Abdullah Muhammad bin Musa alKhwarizmi wrote several works on astronomy, geography and mathematics. His book "Kitab ul-Jabr ve Mukabele" (Algebra) was translated into Latin. Al-Khwarizmi was the founder of not only algebra, but also trigonometry. All world's mathematics used his works in medieval centuries.

Al-Farabi who was the great thinker of the East, and Muslim world, wrote numerous works on philosophy and logic. In the work "Ihsa ul-Ulim" ("Number of Sciences"), Al-Farabi gives a classification of sciences. He is considered the founder of the science of logic after Aristotle. One of the great scientists of Central Asia and the whole East was Abu Reyhan bin Muhammad al-Biruni Al-Khwarizmi (973-1048). The scientist-encyclopedist lived in Ghazna and wrote over 100 works on philosophy, history, geography, mathematics, astronomy, mineralogy, physics, etc. He proved the rotation of the Earth around the Sun the first 500 years before Copernicus.

The great and prominent scholar of the East Ibn Sina is glorified as "Avicenna" in Europe. Ibn Sina wrote a 5-volume book about medicine "Al-Qanun fit-tibb" (Law of Medical Science), an encyclopedia of philosophical works "Ash-Shafa", "Al-Fisul", etc. He was the only surgeon in the whole East and wrote 250 major works. His disciple the great Azerbaijani philosopher Bakhmanyar ibn Marzban played an essential role in the development of world philosophy.

One of the great poets of the East, whose name was included in the list of classics of world poetry, was Nizami (Ilyas) Ganjavi. The immortal "Khamsa" Nizami glorified him all over the world. He created the philosophy of an ideal state, ahead of Thomas More and Tomaso Campanella.

Destuctive Mongolian campaigns and wide spread conquests in the XIII-XV centuries caused great damage to the political, socio-economic and cultural life of the Turkic peoples in the East. Meanwhile, some achievements in science and literature were noticeable. In 1259, under the leadership of the great Azerbaijani scientist with encyclopedic knowledge of Nasiraddin Tusi, prominent person in the whole world, an observatory was built in Maragha. After his death, this place was taken by his son Sadraddin, also famous scientist in the East. In this observatory worked more than a hundred scientists from many 
countries of the world. It was the first academy in the East. The studies carried out here and the writings that have been written form the basis of European science. The tables compiled at the Maragha Observatory were more accurate than the current five-figure geometric tables.

The book of the greatest scientist, Nasiraddin Tusi "Zij Ilkhani" ("Tables of Elkhani") very quickly became known throughout Europe and in the Muslim world. In the issues of the concept of numbers NasiraddinTusi for 400 years ahead of European science. The book "Tahriri-Eglides" ("Interpretation of Euclid") influenced the work of prominent European scholars 